\title{
Inclusão: a expectativa do professor quanto ao desempenho acadêmico do aluno surdo
}

Andreza Marques de Castro Leão

Maria da Piedade Resende da Costa

Palavras-chave: avalição de

desempenho; rendimento escolar;

surdos.

\section{Resumo}

Analisa as expectativas dos professores quanto ao desempenho escolar dos alunos surdos incluídos, comparando-o ao dos ouvintes, e, a partir disso, verificar os efeitos para situações de sucesso ou fracasso escolar. Os instrumentos utilizados foram: um questionário, notas acadêmicas nas disciplinas de Língua Portuguesa e Matemática, análise da produção acadêmica e diário de campo. Participaram do estudo 16 professoras de alunos surdos incluídos nas redes de ensino públicas (estadual e municipal) e particular da cidade de São José dos Campos, SP. As professoras avaliaram 32 alunos, sendo 16 surdos e 16 ouvintes. Quanto aos alunos surdos, verificou-se terem demonstrado um desempenho acadêmico inferior ao apresentado pelos ouvintes: as notas por eles obtidas nas duas disciplinas consideradas no estudo foram inferiores às dos alunos ouvintes. Quanto à produção acadêmica e anotações do diário de campo, foi verificado também diferença entre eles, sendo que os surdos demonstraram mais dificuldades que os ouvintes para realizar as atividades. Os resultados mostram que as expectativas dos professores quanto ao aspecto acadêmico desses alunos são compatíveis, ou seja: realmente, os alunos surdos apresentaram um rendimento acadêmico inferior ao obtido pelos ouvintes. Inúmeras são as implicações educacionais desta constatação, tanto no que se refere à formação do professor quanto à prática pedagógica por ele adotada e suas repercussões no desenvolvimento, na aprendizagem e na motivação dos alunos. Para que isso não interfira negativamente no desempenho acadêmico dos alunos surdos, faz-se necessário preparar adequadamente os docentes.

\section{Introdução}

A escolarização dos alunos com Necessidades Educacionais Especiais (NEEs) tem sido objeto de estudos, discussões e controvérsias ao longo dos anos. Diante do cenário atual, esses alunos têm acesso à escolarização sob três modalidades, quais sejam: segregação (instituições públicas ou privadas nas quais são atendidos), sala de recursos (complementa o processo pedagógico das classes comuns) e alunos que estão no ensino regular (escola inclusiva).

De acordo com Stainback e Stainback (1999), os locais segregados são prejudiciais porque alienam os alunos, pois, neles, estes recebem pouca informação útil à vida real. Já no ensino regular os alunos têm a 
oportunidade de adquirir habilidades para o trabalho, assim como para a vida em comunidade. Além disso, os professores também são beneficiados, pois aprendem a agir e a interagir com alunos com NEEs.

A sala de recursos é uma outra alternativa educacional ao indivíduo com NEEs, na qual o professor especializado poderá dar suporte ao processo pedagógico das classes comuns e complementá-lo; ela foi definida pelo (então) Ministério da Educação e do Desporto (MEC) como: local com equipamentos, materiais e recursos pedagógicos específicos à natureza das necessidades especiais do alunado, onde se oferece a complementação do atendimento educacional realizado em classes do ensino comum. $\mathrm{O}$ aluno deve ser atendido individualmente ou em pequenos grupos, por professor especializado, e em horário diferente do que freqüenta no ensino regular (Brasil, 1994a).

Entretanto, o atendimento dos alunos nessas salas é geralmente comprometido pela falta de profissional especializado e de equipamentos, bem como de materiais pedagógicos adequados.

De acordo com Leão (2004), o "trabalho" desenvolvido nas salas de recursos sem condições adequadas se assemelha ao que ocorre na sala comum. Devido a isso, a referida autora defende a inclusão dos alunos com NEEs, entre estes os surdos, exclusivamente na sala comum do ensino regular.

A escola comum passou a receber esses alunos por ter a Constituição de 1988 determinado o "atendimento educacional especializado aos portadores de deficiência, preferencialmente na rede regular de ensino" (art. 208, III). Além disso, de acordo com a Declaração de Salamanca (Brasil, 1994b), as escolas regulares são consideradas os meios mais eficazes para combater as atitudes discriminatórias, criando assim uma educação para todos. Deste modo, o Brasil adotou esta proposta, ou seja, o compromisso com a construção de um Sistema Educacional Inclusivo.

A inclusão educacional dos educandos com NEEs tem vista ampla, considerando que a convivência na adversidade proporciona maiores possibilidades de desenvolvimento a todos os alunos, tanto no aspecto acadêmico quanto no social, e tem amparo no princípio de igualdade defendido na Constituição Federal (art. 5 ${ }^{\circ}$, aliado ao direito à educação constante do art. 208). Também a Lei $\mathrm{n}^{\mathrm{O}}$ 9.394, de 20 de dezembro de 1996, que estabelece as Diretrizes e Bases da Educação Nacional (Brasil, 1996), reforça o "dever do Estado com a educação escolar pública" mediante a garantia de "atendimento educacional especializado gratuito aos educandos com necessidades especiais [...]" (art. $4^{\circ}$, III).

A educação inclusiva é a prática de inclusão de todos os alunos, independentemente de suas deficiências, em escolas e salas de aula adequadas, de modo que haja o aprendizado do conteúdo acadêmico ministrado. O desafio desse ensino é o de desenvolver uma pedagogia centrada na criança e capaz de educar a todo e qualquer aluno no ensino regular, independentemente de suas condições físicas ou origem social e cultural, com sucesso (Bueno, 2001).

Considera-se que a inclusão representa um avanço em relação aos demais movimentos direcionados aos educandos com NEEs, pois, neste processo, segundo mencionam Glat e Nogueira (2002), há uma mudança do foco na sua educação, em que o ensino é que deve se adaptar às necessidades dos alunos, ao invés de propor a adaptação destes ao conteúdo preconcebido.

Em relação à meta da inclusão, de acordo com Mantoan (1998, p. 31), é não deixar ninguém fora do sistema escolar, o qual terá de se adaptar às particularidades de todos os alunos. A inclusão não prescreve a individualização do ensino para os alunos com "deficiência", mas que se diminuam ou se eliminem os obstáculos que impedem que todos os alunos progridam, tornando a inserção a mais equilibrada possível. Além disso, o aperfeiçoamento de qualidade do ensino regular e a adoção de princípios educacionais válidos para todos os alunos resultarão naturalmente na inclusão escolar dos alunos "deficientes".

Glat (1998) trata sobre a necessidade de modificação do modelo de educação atual na direção da meta da inclusão, mencionando a importância de mudanças estruturais imprescindíveis para a sua implementação. Entre estas, cita a necessidade de planejamento centrado no aluno, que recebe suporte dentro de sua própria classe, com modificações metodológicas e adaptações curriculares em sala. Mendes (2002) também relata sobre a necessidade de mudanças para que o processo inclusivo obtenha êxito, pois refere que os alunos com NEEs têm acesso apenas a um carteira comum, em uma escola comum.

A referida autora relata ainda que, atualmente, as propostas essencialmente ideológicas e com posições radicais são 
preocupantes, considerando que a filosofia da "inclusão" pode servir de justificativa para a extinção das classes ou escolas especiais, ou mesmo de outros tipos de serviços ou programas especializados que atendam as necessidades educacionais especiais dos educandos, assim como para não pressupor (e conseqüentemente custear no futuro), nas novas reformas da política educacional, programas especializados que envolvam medidas necessárias, tais como formação de docentes e mudanças na organização, gestão e financiamentos das escolas, para atender os alunos com NEEs.

Tornar realidade a educação inclusiva, por sua vez, não se efetuará simplesmente por decreto, sem que se avalie as reais condições que possibilitem a inclusão gradativa, contínua, sistemática e planejada de crianças com necessidades educativas especiais nos sistemas de ensino. Deve ser gradativa, por ser necessário que tanto os sistemas de educação especial como os do ensino regular possam ir se adequando à nova ordem, construindo práticas políticas, institucionais e pedagógicas que garantam o incremento da qualidade do ensino, que envolve não só os alunos com necessidades educativas especiais, mas todo o alunado do ensino regular (Bueno, 1999, p. 12).

A inclusão é um processo e, como tal, deve ser paulatinamente conquistada (Carvalho, 1997). "Trata-se de uma mudança de paradigma, numa cultura que não está acostumada a conviver com o seu membro 'diferente' e, realmente, qualquer mudança precisa ser conquistada gradativamente" (Capellini, 2002, p. 6).

De acordo com Reis (1996, p. 44), para se obter a inclusão educacional dos alunos com surdez, devem existir condições humanas e materiais nas escolas que se proponham desempenhar um papel de escola inclusiva de modo a garantir o alcance possível desta meta. Esta autora afirma que o êxito na inclusão destes alunos é relativo, pois é preciso considerar o desenvolvimento da criança surda de acordo com suas possibilidades.

Atualmente há diferentes alternativas educacionais para alunos com surdez. Em relação à inclusão destes na escola de ensino regular, constatam-se opiniões divergentes entre os estudiosos: alguns argumentam a favor (Sassaki, 1997; Sacaloski, 2001) e outros advogam contra (Quadros, 1997; Reis, 1996). Considera-se a necessidade de estudos mais aprofundados referentes à inclusão dos alunos surdos, com o intuito de propiciar conhecimentos mais específicos sobre como ocorre tal inclusão. Devido à complexa condição do surdo no ensino regular, Pedroso (2001) sugere que o seu processo educacional precisa ser acompanhado sistemática e criteriosamente, evitando as avaliações superficiais, incapazes de revelar a realidade deste processo. Para a citada autora, o ideal é que o aluno surdo aprenda independentemente do modelo educacional no qual está inserido.

De acordo com Capellini (2002, p. 36), há diversas maneiras de avaliar o processo de inclusão de alunos com NEEs, entre elas, um pouco investigada no Brasil, a verificação do rendimento acadêmico. O sucesso escolar garante à criança um desempenho valorizado pela sociedade, e, por outro lado, o insucesso acadêmico pode acarretar um senso de não cumprimento da sua tarefa psicossocial de desenvolvimento. Segundo a autora, portanto, verificar o rendimento acadêmico seria uma das formas de avaliar um dos aspectos do processo de inclusão educacional.

Reis (1996) considera que há poucos estudos com a finalidade de avaliar as experiências de inclusão de alunos surdos, e, mesmo assim, eles têm enfrentado dificuldades em comparar os resultados alcançados pelas crianças integradas com os obtidos pelas educadas em escolas especiais, além de outras em relação às atitudes dos professores, pais e profissionais da área, bem como da própria instituição que se propõe desenvolver programas de inclusão escolar.

Machesi (1987) realizou estudos sobre o desenvolvimento de indivíduos surdos incluídos nas classes comuns, tendo constatado melhoras quanto aos aspectos de integração social, adaptação e linguagem oral, quando comparados àqueles que viviam em internato para surdos. Num outro estudo direcionado a professores de crianças surdas, ela questionou se seria possível, dadas as condições adequadas a essas crianças, a sua satisfatória integração. De acordo com os participantes, faz-se necessário conseguir que o sistema educativo e a escola comum tenham recursos, meios humanos e materiais, para que essas crianças possam progredir sendo nesta escolarizadas.

Sacaloski (2001) também é autora de um estudo sobre a inclusão escolar de pessoas surdas, do qual participaram alunos ouvintes e outros com surdez, além de professores e pais, sendo os alunos avaliados 
quanto ao desenvolvimento comunicativolingüístico gráfico e acadêmico. Para isso, a pesquisadora utilizou compreensão de textos, tarefas acadêmicas de soma e subtração e resolução de problemas. Em relação a estes aspectos, foi constatado que os alunos surdos apresentaram desempenho acadêmico pior que o dos alunos ouvintes. Além disso, o estudo enfocou a opinião dos pais, professores e alunos sobre a inclusão escolar de pessoas com surdez, tendo a maioria considerado que o aluno surdo deve estudar em classe comum e que ele é capaz de acompanhar a turma com desempenho satisfatório.

Outro estudo realizado com professores de alunos surdos foi o de Buffa (2002), que visava analisar a opinião desses profissionais do ensino regular a respeito da inclusão de alunos surdos, bem como a sua formação para atender alunos com tal deficiência. Participaram dessa pesquisa 196 professores da rede regular de ensino da cidade de Bauru, SP, que atuavam em classes comuns no nível de educação infantil e primeiro ciclo do ensino fundamental. A pesquisadora verificou que esses professores, na sua maioria, se posicionaram a favor da inclusão dos alunos surdos na classe regular, desde que o número de alunos em sala de aula seja reduzido, exista apoio da sala de recursos e recebam orientação de profissionais especializados no atendimento desses alunos, pois se sentem despreparados para lidar com alunos surdos, por não possuírem conhecimentos suficientes sobre a surdez.

Com relação ao desempenho acadêmico dos alunos surdos incluídos, Reis (1996) relata que os estudos realizados indicam que, embora eles apresentem dificuldade escolar, seu desenvolvimento acadêmico pode ser considerado satisfatório. Essa autora sugere que a perda auditiva seja o principal fator que determina o rendimento acadêmico e o desenvolvimento individual e que o rendimento da criança surda é melhor em escolas integradoras que em escolas especiais.

Capellini (2002) realizou um estudo em que é avaliado o rendimento escolar de 89 alunos de escolas públicas portadores de diferentes deficiências, entre estas a auditiva, com a utilização do Instrumento de Avaliação do Repertório Básico para Alfabetização (IAR) - habilidades de educação Infantil - e do Teste do Desempenho Escolar (TDE) - leitura, escrita e aritmética, além de um questionário sobre desempenho escolar e boletim acadêmico. Em relação aos resultados quanto ao rendimento acadêmico de alunos com deficiência auditiva, a autora constatou que chama a atenção a discrepância entre os resultados nas áreas de Língua Portuguesa e Matemática. Em geral, o desempenho em Língua Portuguesa, especificamente em leitura, apresentou-se muito similar ao dos alunos com deficiência mental, o que parece tornar este ponto também crítico para esse tipo de alunado. A dificuldade com a Língua Portuguesa oralizada e escrita para esses alunos pode ser um fator primordial que justifique esse baixo rendimento escolar. Seria interessante investigar para esse grupo se haveriam diferenças no rendimento em função do tipo de comunicação utilizada. No caso dos grupos de alunos aqui estudados foram encontrados tanto alunos que oralizavam quanto alunos que utilizavam a língua de sinais, e esse fato não foi considerado.

De acordo com Bueno (1994, p. 35), "para que as crianças surdas sejam beneficiadas num ambiente inclusivo, as mesmas deverão ter supridas as necessidades inerentes à deficiência sensorial que apresentam". Ele também afirma que esta deficiência não acarreta qualquer déficit cognitivo, mas as possíveis dificuldades cognitivas apresentadas por essas crianças estão diretamente relacionadas ao desenvolvimento da linguagem, o que deveria resultar em bom rendimento escolar, desde que supridas as dificuldades específicas de linguagem. Neste sentido considera-se essencial o desenvolvimento de programas de reabilitação.

De modo geral, a avaliação do desempenho escolar dos alunos com NEEs, conforme a Deliberação CEE n ${ }^{\circ}$ 05/00, deverá ser contínua e cumulativa, com prevalência dos aspectos qualitativos sobre os quantitativos. Essa verificação deve ter como referência os itens básicos relativos à programação escolar, ser voltada à detecção de qualquer progresso no aproveitamento escolar, visando à constante melhoria das condições de ensino (São Paulo, 2000).

A avaliação é parte integrante do processo ensino-aprendizagem e exige dos profissionais envolvidos preparo técnico e grande capacidade de observação, para que possam detectar, diariamente, os pontos de conflitos geradores do fracasso escolar. Esses pontos detectados devem ser utilizados pelo professor como referenciais para os necessários ajustes nas ações pedagógicas, objetivando um melhor desempenho do aluno. 
As pesquisas metodológicas sobre ensino-aprendizagem passaram a considerar as crenças e as expectativas dos professores como aspectos que podem afetar o desempenho e o rendimento dos alunos. As atribuições de casualidade dos professores para o sucesso e o fracasso escolar dos seus alunos influenciam as expectativas de sucesso e fracasso destes e, também, o seu desempenho acadêmico (Martini, Del Prette, 2002).

De acordo com Martini e Del Prette (2002), as expectativas dos docentes podem afetar as características da relação professor-aluno e, por essa via, o desempenho e rendimento do aluno. Assim como acontece em toda relação humana, a relação professor-aluno também é passível de expectativas. O problema reside em que a força da expectativa do professor em relação ao aluno tem um peso determinante muito grande, pois implica não só o desempenho do aluno naquele momento, mas poderá influenciá-lo ao longo de sua vida (Freire, 2000). Desse modo, segundo este autor, o desempenho acadêmico do aluno pode estar diretamente contaminado pela expectativa do professor em relação a ele.

Via de regra, atribui-se a culpa do rendimento escolar ao aluno, sem levar em conta a predisposição do professor: "a expectativa, como representação social reelaborada pelo professor, gera distorções que sustentam expectativas de fracasso e atribuem a responsabilidade deste aos alunos" (Ribeiro, Bregunci, 1986, p. 70).

A expectativa do professor quanto à aprendizagem dos alunos com NEEs parece estar associada às características individuais de cada aluno (Parizzi, 2000). De modo geral, verifica-se que a expectativa do professor quanto ao aprendizado destes alunos exerce influência no processo inclusivo, pois pode implicar em delimitar ou maximizar a possibilidade de aprendizado deles.

Segundo Artrolli (1999), as expectativas dos professores quanto aos alunos com deficiências estão relacionados às dificuldades, pois os docentes antecipadamente já percebem os alunos que terão dificuldades e imaginam que, dependendo da deficiência, o processo inclusivo será mais complexo. Além disso, a referida autora relata que, no contexto da sala de aula, espera-se que os alunos produzam, aprendam com facilidade e atendam às expectativas dos professores.
Rosenthal e Jacobson (1983), num estudo denominado Pigmalion in the classroom, destacam as influências das percepções dos professores em sua prática profissional e, conseqüentemente, no desempenho acadêmico de seus alunos. Esse estudo trouxe uma contribuição valiosa à educação, por mostrar a importância e os efeitos das expectativas do professor em relação a esse desempenho. Estes autores realizaram um experimento para testar a hipótese de que, numa dada classe, as crianças realmente apresentariam um desempenho acadêmico, e perceberam que 20\% deles eram academicamente acelerados e tinham alto QI. No final do ano letivo, comprovaram, por meio de testes, que esses alunos realmente tinham obtido ganhos em pontos de QI e, em vista disso, lançaram várias hipóteses para explicar a ocorrência de tais resultados, sendo a mais aceita a de que o professor transmite suas expectativas positivas ou negativas a seus alunos, mediante as interações que com eles estabelece em sala de aula; assim, este profissional dá mais atenção aos alunos considerados com bom desempenho acadêmico e menos aos que apresentam dificuldades acadêmicas. Os autores consideram que as expectativas do professor exercem grande influência sobre o desempenho acadêmico de seus alunos e que, caso elas sejam positivas, aumentam a auto-estima, favorecendo a melhora do desempenho.

No estudo de Silva e Pereira (2003), os professores consideraram que seus alunos surdos apresentavam condições de ter uma aprendizagem normal, ilimitada, mas que ocorre de modo diferente, já outros afirmam que a aprendizagem desses alunos é normal porque há alunos ouvintes com mais dificuldades que eles. A implicação de uma ou de outra posição é a baixa expectativa dos professores em relação à aprendizagem do aluno surdo; apesar da imagem de que a aprendizagem do aluno surdo é normal, muitos acabam admitindo que o aluno surdo não está aprendendo. Para justificar as dificuldades de aprendizagem dos alunos, alguns professores mencionam o seu despreparo (do docente), a quantidade de alunos na sala de aula, a falta de assessoria, entre outros. Conforme afirmam estas autoras, existe uma predisposição maior ou menor para aceitar o aluno surdo.

Segundo Bencini (2001), o principal obstáculo para a efetiva inclusão de alunos com NEEs está na expectativa dos professores quanto à capacidade de aprendizagem desses alunos. Considera ainda que eles 
vêem o deficiente sensorial como incapacitado para aprender, por achar que este déficit acarreta problemas cognitivos e, assim, agrava o intelecto. Em relação aos alunos que apresentam deficiência sensorial, tem-se o aluno surdo.

Pollack (1985) afirmou que, na classe comum, há uma enorme expectativa desses profissionais para que o desempenho do aluno surdo seja igual ou melhor que o do aluno ouvinte, e essa expectativa inicial pode conduzir à realização de ações que a tornem verdadeira, podendo ser vista como profecia auto-realizadora. Segundo Good (1987, p. 32), o professor espera que o aluno mantenha os padrões de comportamento mostrados anteriormente, de tal modo que toma esses comportamentos como imutáveis e não consegue ver e aproveitar as mudanças potenciais.

Essa afirmação condiz com o relato de Artrolli (1999), no qual considera que a expectativa que se tem perante a pessoa deficiente implica delimitar a sua possibilidade de desenvolvimento e de aprendizagem.

De acordo com Glat (1998), citado por Glat e Nogueira (2002), a segregação social e a marginalização de indivíduos com NEEs apresentam raízes profundas, sendo que a inclusão educacional destes, envolve, entre outros fatores, a representação que as pessoas (no caso, os professores) têm sobre os alunos com deficiências e como determinam o tipo de reação que se estabelece com estes. De acordo com Artrolli (1999), a preconcepção quanto ao aprendizado desses indivíduos pode implicar barreiras à sua aprendizagem em classe comum, pois esta se concretiza na postura do professor ante o alunado.

Percebe-se, assim, a influência exercida pela expectativa dos professores. Deste modo, constata-se a necessidade de estudos mais aprofundados, a fim de se obter conhecimento sobre a expectativa dos professores de classe comum quanto ao desempenho acadêmico dos alunos surdos incluídos, bem como verificar os efeitos dessa expectativa.

Com base nestas considerações, o presente estudo objetivou analisar as expectativas dos professores quanto ao desempenho escolar dos alunos surdos incluídos, comparando-o ao dos ouvintes, e, a partir disso, verificar os efeitos para situações de sucesso ou fracasso escolar.

\section{Material e métodos}

A pesquisa foi realizada na cidade de São José dos Campos, SP, em cinco escolas públicas (quatro estaduais e uma municipal) e duas particulares, durante o ano de 2003. Dela participaram 16 professoras do ensino fundamental, das redes de ensino público (estadual e municipal) e particular, que atuavam em salas regulares com alunos surdos, tendo sido por elas avaliados 32 alunos: 16 ouvintes e 16 surdos. Os alunos ouvintes foram escolhidos pela pesquisadora mediante sorteio, a fim de evitar qualquer tipo de interferência, e os alunos surdos eram todos incluídos em classes das escolas que participaram do estudo. Em todas as salas de aula havia apenas um aluno surdo incluído.

A fim de constatar o número de crianças surdas incluídas nas classes regulares do ensino fundamental, foi necessário um levantamento inicial em todas as escolas públicas da cidade (70), mediante o qual verificou-se a existência de apenas sete escolas estaduais e cinco municipais com alunos surdos incluídos. Com relação às escolas particulares, num total de 25, foi verificado que quatro delas apresentavam alunos surdos incluídos em classes comuns. Nessas 16 escolas, 40 professores atuavam com alunos surdos, 20 dos quais (50\%) constituiriam a amostra representativa das escolas de diferentes regiões da cidade; contudo, apenas 16 docentes se dispuseram a participar do estudo.

No que se refere à coleta de dados, primeiramente foram feitas visitas às escolas, a fim de apresentar aos seus diretores a carta de informação e termo de consentimento e solicitar autorização para a realização da pesquisa. Após a concordância dos diretores, foram agendados os dias e horários em que fosse possível o contato com os professores nas escolas, sem interferir em suas atividades acadêmicas. Nesse primeiro contato, foram também apresentados a carta de informação e o termo de consentimento aos professores, para que eles tivessem conhecimento do que seria abordado no estudo, e solicitada a sua aceitação para dele participarem. Os questionários eram entregues aos professores, e, após uma semana, era solicitada a sua devolução à pesquisadora.

Foram utilizados na realização da pesquisa os seguintes instrumentos: questionário, notas acadêmicas, produção acadêmica e diário de campo. Os dados obtidos por 
meio dos instrumentos foram organizados em tabelas e gráficos, para posterior realização da análise qualitativa e quantitativa.

O questionário continha 10 questões referentes ao aspecto acadêmico dos alunos (surdos e ouvintes), sendo que, primeiramente, eram registrados os seus dados de identificação, tais como nome, sexo, idade, série, escola que freqüentava, se apresentava perda auditiva, caracterização desta perda, se fazia uso de Aparelho de Amplificação Sonoro Individual (AASI) e se recebia acompanhamento pedagógico e fonoaudiológico. Além disso, o instrumento reunia 10 questões sobre a expectativa do professor quanto aos alunos, englobando os seguintes aspectos: potencial e rendimento acadêmico; tarefas acadêmicas; compreensão da matéria; trabalhos e notas acadêmicas; e, finalmente, expectativa do docente quanto ao aluno.

Os diferentes aspectos considerados no estudo, no que diz respeito a esses alunos, podem ser visualizados no Quadro 1. Nele, pode-se constatar que havia alunos surdos de ambos os sexos, com idades de 8 a 17 anos, e que freqüentavam diferentes séries e escolas do ensino fundamental, pertencentes às redes estadual, particular e municipal.

Quanto ao uso de AASI, mais da metade desses alunos o utilizava; já em relação ao acompanhamento fonoaudiológico, 11 deles o recebiam, enquanto que apenas cinco tinham acompanhamento pedagógico.

Quanto à abordagem educacional, observou-se que todos os alunos surdos eram ensinados por meio do oralismo, não tendo nenhuma outra para auxiliá-los (libras, gestos, etc.). Além disso, a inclusão educacional não é total, o que justifica alguns alunos apresentarem outros serviços auxiliares, como o acompanhamento de fonoaudiólogos e pedagogos.

\section{Quadro 1 - Características dos alunos surdos}

\begin{tabular}{|c|c|c|c|c|c|c|c|}
\hline Aluno & Sexo & $\begin{array}{l}\text { Idade } \\
\text { (anos) }\end{array}$ & $\begin{array}{l}\text { Série que } \\
\text { freqüenta }\end{array}$ & Escola & $\begin{array}{l}\text { Uso do } \\
\text { AASI }\end{array}$ & $\begin{array}{l}\text { Acompanhamento } \\
\text { fonoaudiológico }\end{array}$ & $\begin{array}{c}\text { Acompanhamento } \\
\text { pedagógico }\end{array}$ \\
\hline $\mathrm{A} 1$ & $\mathrm{~F}$ & 12 & $4^{a}$ & Estadual & Não & Não & Não \\
\hline $\mathrm{A} 2$ & $\mathrm{~F}$ & 10 & $4^{a}$ & Estadual & Não & Sim & Não \\
\hline A3 & $\mathrm{F}$ & 13 & $3^{a}$ & Estadual & Sim & Sim & Não \\
\hline A4 & $\mathrm{F}$ & 10 & $4^{a}$ & Estadual & Sim & Sim & Não \\
\hline A5 & $\mathrm{F}$ & 8 & $2^{a}$ & Estadual & Não & Sim & Não \\
\hline A6 & $\mathrm{F}$ & 8 & $3^{a}$ & Estadual & Sim & Não & Não \\
\hline A7 & $F$ & 17 & $8^{a}$ & Estadual & Sim & Não & Não \\
\hline A8 & $\mathrm{F}$ & 15 & $8^{a}$ & Estadual & Não & Não & Não \\
\hline A9 & $\mathrm{F}$ & 13 & $7^{a}$ & Particular & Sim & Sim & Não \\
\hline A10 & $M$ & 14 & $5^{a}$ & Particular & Sim & Sim & Sim \\
\hline $\mathrm{A} 11$ & $M$ & 8 & $1^{a}$ & Particular & Não & Sim & Sim \\
\hline A12 & $M$ & 9 & $3^{a}$ & Particular & Não & Sim & Sim \\
\hline A13 & $\mathrm{F}$ & 9 & $3^{a}$ & Particular & Sim & Sim & Sim \\
\hline $\mathrm{A} 14$ & $M$ & 8 & $2^{a}$ & Municipal & Sim & Sim & Sim \\
\hline A15 & $\mathrm{F}$ & 14 & $8^{a}$ & Estadual & Não & Não & Não \\
\hline A16 & $M$ & 10 & $3^{a}$ & Particular & Sim & Sim & Não \\
\hline
\end{tabular}

Por meio do Quadro 2 pode-se observar diferentes aspectos considerados quanto aos alunos ouvintes: eram eles alunos de ambos os sexos, com predominância do sexo masculino $(68,75 \%)$, com idades variando de 8 a 15 anos e freqüentando diferentes séries do ensino fundamental, em escolas estaduais, particulares e municipal. 
Quadro 2 - Características dos alunos ouvintes

\begin{tabular}{|c|c|c|c|c|}
\hline Aluno & Sexo & $\begin{array}{l}\text { Idade } \\
\text { (anos) }\end{array}$ & $\begin{array}{l}\text { Série que } \\
\text { freqüenta }\end{array}$ & Escola \\
\hline A17 & $M$ & 12 & $4^{a}$ & Estadual \\
\hline A18 & M & 10 & $4^{a}$ & Estadual \\
\hline A19 & $M$ & 13 & $3^{a}$ & Estadual \\
\hline A20 & M & 10 & $4^{a}$ & Estadual \\
\hline $\mathrm{A} 21$ & $M$ & 8 & $2^{a}$ & Estadual \\
\hline A22 & $M$ & 8 & $3^{a}$ & Estadual \\
\hline A23 & M & 15 & $8^{a}$ & Estadual \\
\hline A24 & $M$ & 15 & $8^{a}$ & Estadual \\
\hline A25 & M & 13 & $7^{a}$ & Particular \\
\hline A26 & $\mathrm{F}$ & 14 & $5^{a}$ & Particular \\
\hline A27 & $\mathrm{F}$ & 8 & $1^{a}$ & Particular \\
\hline A28 & $F$ & 9 & $3^{a}$ & Particular \\
\hline A29 & $M$ & 9 & $3^{a}$ & Particular \\
\hline A30 & $\mathrm{F}$ & 8 & $2^{a}$ & Municipal \\
\hline A31 & $M$ & 14 & $8^{a}$ & Estadual \\
\hline A32 & $\mathrm{F}$ & 10 & $3^{a}$ & Particular \\
\hline
\end{tabular}

Foram utilizadas diferentes categorias de resposta nos gráficos. Por meio do Quadro 3 pode-se observar a correspondência em porcentagem de cada categoria considerada.

Quadro 3 - Categorias de resposta dos Gráficos

\begin{tabular}{|c|c|}
\hline Categorias & Porcentagem (\%) de Incidência \\
\hline Muito bom & 90 a $100 \%$ \\
\hline Bom & 70 a $85 \%$ \\
\hline Regular & 65 a $50 \%$ \\
\hline Ruim & 45 a $25 \%$ \\
\hline Péssimo & inferior a $25 \%$. \\
\hline Muito acima & 90 a $100 \%$ \\
\hline Acima & 70 a $85 \%$ \\
\hline Na média & 65 a $50 \%$ \\
\hline Abaixo & 45 a $25 \%$ \\
\hline Bem abaixo & inferior a $25 \%$. \\
\hline Sempre & 90 a $100 \%$ \\
\hline Freqüentemente & 70 a $85 \%$ \\
\hline Às vezes & 65 a $50 \%$ \\
\hline Raramente & 45 a $25 \%$ \\
\hline Nunca & inferior a $25 \%$. \\
\hline
\end{tabular}


Além do questionário, foram utilizadas as notas acadêmicas dos alunos nas disciplinas de Língua Portuguesa e Matemática. A opção por essas disciplinas decorre do fato de constituírem elas a base cujo domínio é indispensável à continuidade dos estudos nos níveis mais avançados.

Outro instrumento utilizado no estudo foi o diário de campo, pois, em algumas escolas, a pesquisadora não tinha como retirar o material acadêmico dos alunos para ser analisado fora delas; deste modo, optou-se pelo diário, por meio do qual a pesquisadora realizava anotações da análise dos cadernos e atividades acadêmicas realizadas pelos alunos.

\section{Resultados e discussões}

Este estudo se propôs analisar a expectativa dos professores quanto a diferentes aspectos acadêmicos dos alunos surdos e ouvintes. Para isto, adotou-se como conduta apresentar os dados em gráficos, a fim de que sejam melhor visualizados os resultados obtidos.

Por meio dos resultados mostrados no Gráfico 1, verifica-se o potencial acadêmico dos alunos, considerando-se este o potencial de aprendizagem que eles apresentavam.

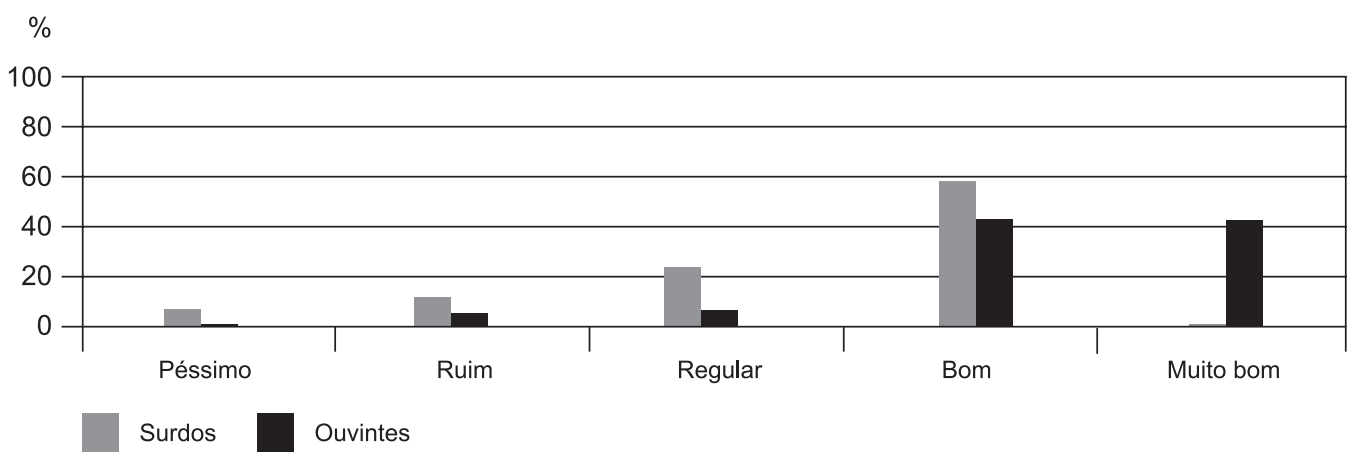

Gráfico 1 - Potencial acadêmico dos alunos

Constatou-se que os alunos surdos, segundo as professoras, apresentavam potencial acadêmico inferior ao obtido pelos alunos ouvintes, pois somente $6,25 \%$ destes foram avaliados como tendo péssimo potencial acadêmico. Além disso, $12,5 \%$ dos surdos foram considerados pelas professoras como tendo um potencial ruim, categoria em que 6,25\% dos estudantes ouvintes foram também enquadrados. Acrescente-se que 25\% dos surdos foram avaliados como apresentando um potencial acadêmico regular, sendo que apenas $6,25 \%$ dos alunos ouvintes foram de igual modo avaliados. Quanto à categoria de bom potencial acadêmico, $56,25 \%$ dos surdos foram desse modo avaliados, contra 43,75\% dos alunos ouvintes; contudo, quanto à categoria muito bom, apenas $43,75 \%$ dos ouvintes foram assim avaliados.
Estes achados permitem concluir que o potencial acadêmico dos alunos ouvintes, segundo as professoras, é superior ao apresentado pelos alunos surdos, pois $87,5 \%$ dos ouvintes foram categorizados como apresentando bom e muito bom potencial, contra $56,25 \%$ dos surdos classificados como bons.

No que se refere ao potencial acadêmico dos alunos, observou-se que as professoras consideraram que a aprendizagem dos alunos surdos difere da apresentada pelos ouvintes.

Estes achados coincidem com o constatado no estudo de Silva e Pereira (2003), que as professoras afirmam que o aluno surdo não apresenta problemas de aprendizagem, mas pode-se observar no discurso delas a imagem de limitação do aluno surdo no que se refere à aprendizagem.

No Gráfico 2 encontram-se demonstrados os dados obtidos quanto ao rendimento acadêmico dos alunos. 
$\%$

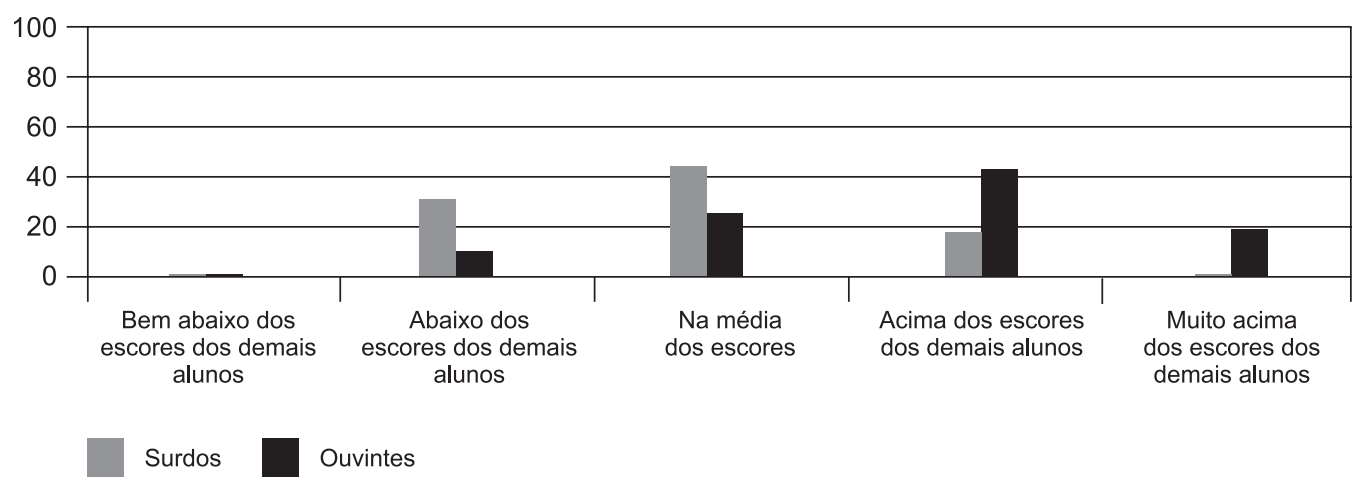

Gráfico 2 - Rendimento acadêmico

No questionário (Anexo 2) foram consideradas diferentes categorias quanto ao rendimento acadêmico, entre elas se os alunos estavam bem abaixo dos escores dos demais, no entanto, nenhum deles recebeu esta avaliação. Já quanto a categoria abaixo dos escores, $31,25 \%$ dos surdos foram assim categorizados, bem como 12,5\% dos estudantes ouvintes. Isso pode evidenciar o cuidado das professoras em avaliar os alunos surdos e ouvintes, demonstrando o receio de categorizá-los como bem abaixo.

Nos demais aspectos, $50 \%$ dos alunos surdos foram avaliados como estando na média dos escores dos demais alunos, e $25 \%$ dos ouvintes receberam esta mesma classificação. Em relação a estarem acima dos escores dos demais alunos, apenas $18,75 \%$ dos surdos foram assim avaliados, enquanto $43,75 \%$ dos alunos ouvintes foram classificados nessa categoria. Além disso, apenas $18,75 \%$ dos alunos ouvintes foram avaliados como estando muito acima dos escores dos demais alunos.

Constatou-se, assim, que $62,5 \%$ dos alunos ouvintes, de acordo com a expectativa das professoras, apresentavam rendimento acadêmico variando de acima a muito acima dos escores dos demais alunos, já apenas $18,75 \%$ os alunos surdos se encontravam nesta mesma categoria. Deste modo, pode-se inferir que, segundo as professoras, os alunos surdos têm um rendimento acadêmico inferior ao apresentado pelos alunos ouvintes, sendo que, no presente estudo, verificou-se que $81,25 \%$ destes estavam na média e abaixo dos escores dos demais alunos.

Estes achados permitem concluir que os alunos surdos não têm correspondido à expectativa das professoras. Conforme afirmam Ribeiro e Bregunci (1986), freqüentemente se atribui a culpa do rendimento escolar ao aluno, sem levar em consideração a pré-disposição do professor, sendo que expectativas geram distorções que sustentam o fracasso escolar e atribuem as responsabilidades aos alunos, havendo, conseqüentemente, uma constante distorção da expectativa.

Outro aspecto avaliado foi quanto à realização adequada das tarefas em classe. Os dados obtidos encontram-se expostos no Gráfico 3.

\section{$\%$}

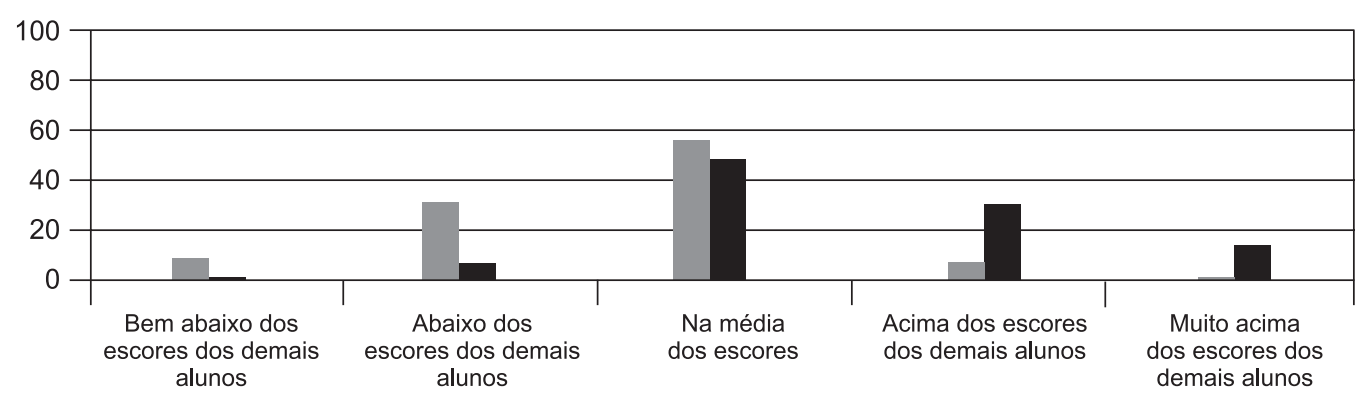

Surdos Ouvintes

Gráfico 3 - Realização adequada das tarefas acadêmicas 
Quanto à avaliação das professoras neste aspecto, verificou-se que somente $6,25 \%$ dos alunos surdos foram classificados como estando bem abaixo dos demais alunos. Além disso, 31,25\% destes alunos foram categorizados como estando abaixo dos demais alunos, contra apenas 6,25\% dos ouvintes situados nesta categorização.

Quanto a categoria média dos escores, verificou-se que $56,25 \%$ dos alunos surdos e $50 \%$ dos ouvintes foram assim avaliados. Nos demais aspectos (acima da média e muito acima da média dos escores dos demais alunos), constatou-se a prevalência dos ouvintes, com somente $6,25 \%$ dos estudantes surdos categorizados como acima da média, enquanto $31,25 \%$ dos ouvintes foram assim considerados. Constatou-se ainda que apenas $12,5 \%$ dos estudantes ouvintes foram tidos como estando muito acima da média dos demais alunos.
Ressalta-se assim que, de modo geral, a maioria dos alunos surdos (56,25\%), segundo a avaliação das professoras, estava na média dos demais alunos no que se refere à realização adequada das tarefas de classe. Já os alunos ouvintes foram avaliados estando na média dos demais alunos (50\%), bem como acima dos demais alunos (31,25\%).

Por meio destes dados pode-se questionar se realmente esses alunos conseguem realizar as tarefas acadêmicas em classe, pois, conforme relatam Silva e Pereira (2003, p. 175), embora as professoras afirmem que a surdez não compromete o desenvolvimento cognitivo, todas fazem menção às dificuldades que eles apresentam na realização das tarefas acadêmicas.

Quanto à necessidade que os alunos apresentam em ter apoio constante para realizar as tarefas acadêmicas, os dados obtidos encontram-se indicados no Gráfico 4.

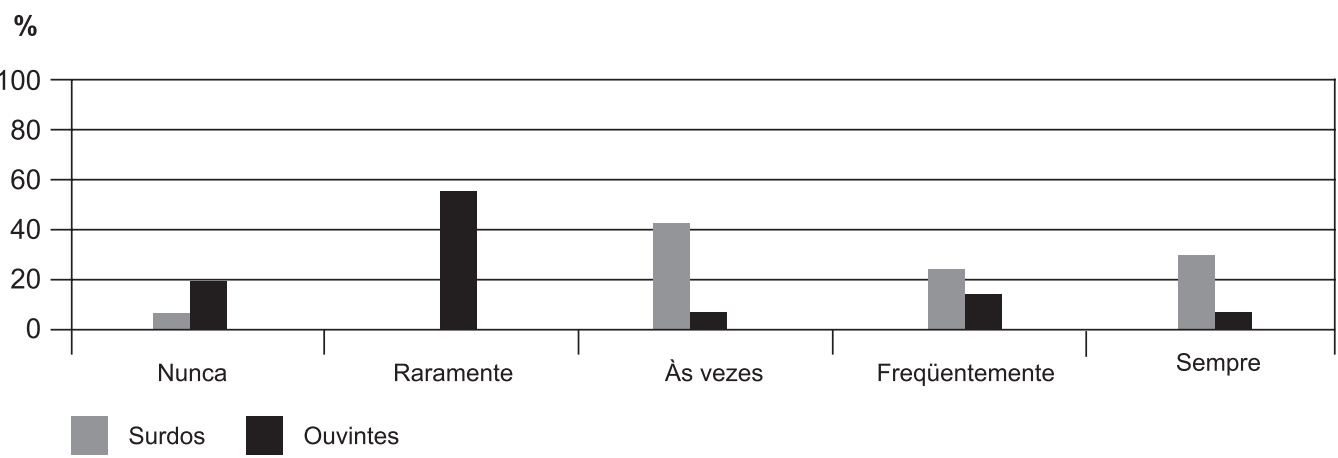

Gráfico 4 - Apoio constante para realizar as tarefas acadêmicas

Verificou-se, por meio dos resultados mostrados no Gráfico 4, que 18,75\% dos alunos ouvintes e $6,25 \%$ dos surdos nunca precisavam de apoio, sendo que $56,25 \%$ dos ouvintes raramente necessitavam de auxílio para realizar suas tarefas.

Constatou-se também que $37,5 \%$ dos alunos surdos às vezes precisavam de apoio para realizar suas tarefas, enquanto apenas $6,25 \%$ dos ouvintes encontravam-se nesta categoria. Além disso, as professoras relataram que $25 \%$ dos surdos freqüentemente precisam de apoio e 31,25\% sempre, para realizar suas tarefas. Quanto aos alunos ouvintes, as professoras afirmaram que apenas $12,5 \%$ deles precisam de apoio freqüentemente e somente $6,25 \%$, sempre.

Com base nestes dados, pode-se afirmar que os alunos surdos necessitam de mais apoio para realizar suas tarefas acadêmicas que os alunos ouvintes. Assim, conforme relata Silva e Pereira (2003, p. 175), as professoras geralmente necessitam auxiliar os alunos surdos, seja facilitando as atividades, seja respondendo por eles ou deixando-os realizar cópia, entre outras formas de apoio. Na medida em que a professora ajuda o aluno a resolver as suas atividades, ela cria neste a imagem de inteligente, o que resulta, muitas vezes, em uma imagem idealizada. Nesta imagem desconsidera-se que a aprendizagem do aluno surdo é normal, ilimitada, mas que ocorre de modo diferente dos alunos ouvintes.

Em relação à compreensão da matéria, a fim de assimilarem o conteúdo acadêmico, os alunos necessitam, por vezes, de mais explicações. Os dados obtidos sobre este aspecto encontram-se indicados no Gráfico 5. 


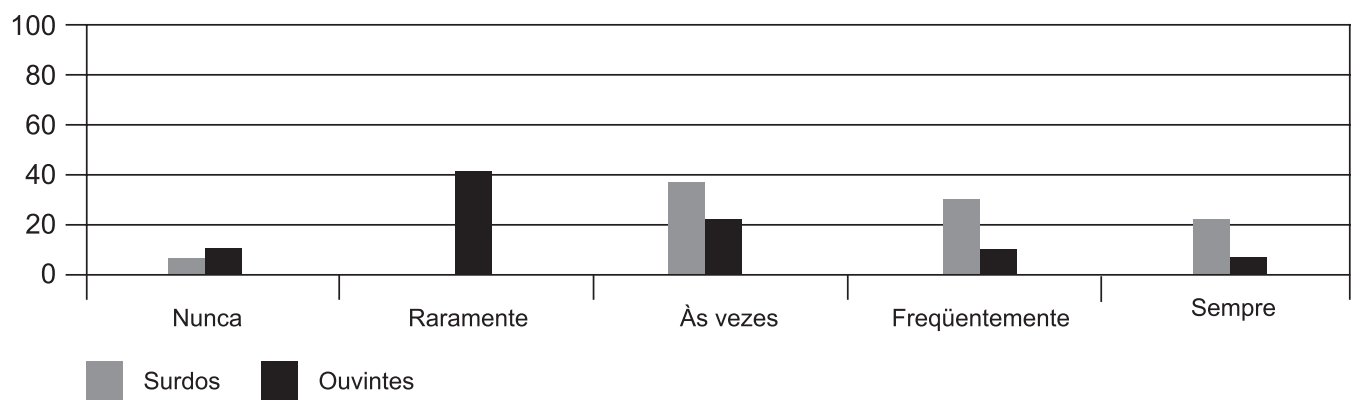

Gráfico 5 - Compreensão - necessidade de mais explicações que os demais alunos

Constatou-se, por meio dos resultados mostrados no Gráfico 5, que 6,25\% dos estudantes surdos e $12,5 \%$ dos ouvintes nunca precisavam de mais explicações, sendo que $43,75 \%$ dos ouvintes raramente necessitam de mais explicações.

Verificou-se ainda que $37,5 \%$ dos surdos e $25 \%$ dos ouvintes às vezes necessitavam de mais explicações que os demais alunos.

De modo geral, verificou-se que os alunos surdos, em sua maioria, necessitavam de mais explicações para compreensão da matéria, visto que as professoras consideraram que, respectivamente, 31,25\% e 25\% deles foram tidos como estudantes que freqüentemente ou sempre precisavam desse tipo de ajuda. Em relação aos alunos ouvintes, quanto a estes aspectos, as professoras mencionaram que 12,5\% deles precisavam freqüentemente de mais explicações e 6,25\%, sempre.

De acordo com Sacaloski (2001), os alunos surdos necessitam de mais explicações para compreender a matéria por apresentarem dificuldade para entender o que lhes é dito. Segundo Glat (1998), é muito difícil imaginar um aluno surdo que apresente domínio da língua oral assistindo uma aula tranqüilamente, pois sua dificuldade de abstração e a falta de vocabulário não permitem que ele receba as informações de forma adequada. Considera-se, então, que esses problemas levem o aluno surdo a ter dificuldades para apreender os conteúdos trabalhados em sala de aula.

A avaliação referente às notas acadêmicas está representada no Gráfico 6 e discutida a seguir.

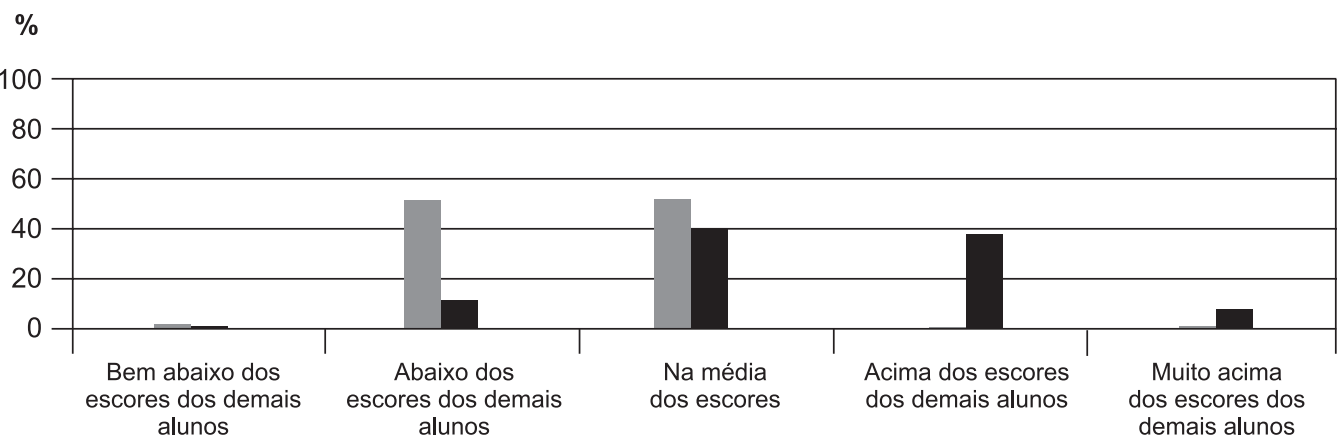

Surdos

Ouvintes

Gráfico 6 - Notas acadêmicas dos alunos 
Por meio dos resultados mostrados no Gráfico 6, observou-se que nenhum dos alunos foi tido como apresentando notas acadêmicas bem abaixo dos escores dos demais alunos.

Dos alunos surdos, metade foi avaliada pelas professoras como apresentando notas acadêmicas abaixo, e a outra metade como as tendo na média dos demais alunos. Já dos estudantes ouvintes, apenas 12,5\% foram tidos pelas professoras como apresentando notas abaixo das dos demais alunos e $43,75 \%$ foram vistos como estando na média dos demais alunos.
Somente os alunos ouvintes foram classificados como estando acima $(37,5 \%)$ e muito acima $(6,25 \%)$ dos demais. Constatou-se, deste modo, que os alunos ouvintes, de acordo com as professoras, apresentavam notas acadêmicas superiores às obtidas pelos alunos surdos, encontrando este estudo o mesmo resultado obtido por Capellini (2002): os alunos surdos apresentaram notas acadêmicas abaixo da média.

Foi considerado no presente estudo também o desempenho acadêmico dos alunos. Pode-se observar no Gráfico 7 os dados obtidos quanto a este aspecto.

$\%$

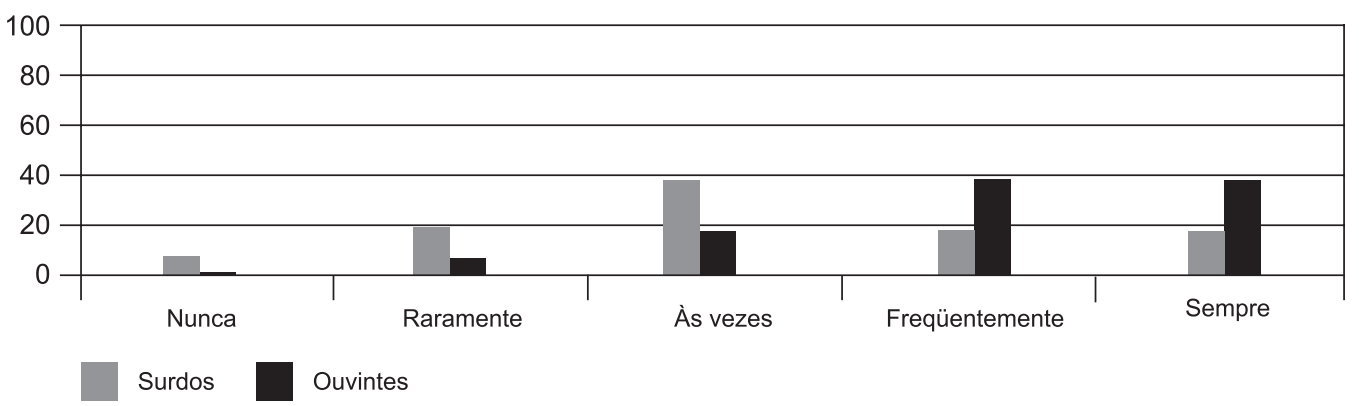

Gráfico 7 - Desempenho acadêmico

Em relação ao desempenho acadêmico, segundo os resultados mostrados no gráfico acima, 6,25\% dos surdos nunca correspondem aos esforços das professoras e, também, $18,75 \%$ deles e $6,25 \%$ dos ouvintes raramente conseguiam corresponder.

Verificou-se ainda que $37,5 \%$ dos surdos e $18,75 \%$ dos ouvintes às vezes conseguiam corresponder, sendo que 18,75\% dos surdos e $37,5 \%$ dos ouvintes freqüentemente o fazem. Além disso, esta mesma porcentagem foi obtida quanto à categoria sempre; deste modo, foi constatada uma porcentagem maior de alunos ouvintes que sempre correspondem ao que os professores esperam.

Como nos demais aspectos avaliados neste estudo, os alunos ouvintes, de acordo com o esperado pelas professoras, apresentaram um desempenho acadêmico superior ao dos alunos surdos. Estes achados coincidem com os obtidos por Sacaloski (2001).

Em relação às notas acadêmicas obtidas pelos alunos na disciplina de Língua Portuguesa, pode-se ter no Gráfico 8 uma visão geral dos quatro conceitos (A, B, C e D) alcançados nos diferentes bimestres do ano de 2003.

Como se vê, os alunos ouvintes obtiveram os melhores conceitos (A e B), enquanto que os alunos surdos preponderam nos inferiores (C e D). Pode-se constatar ainda algo interessante, a inversão de conceitos obtidos pelos alunos, em que os ouvintes obtiveram o melhor conceito (A) e os surdos, o pior (D). 


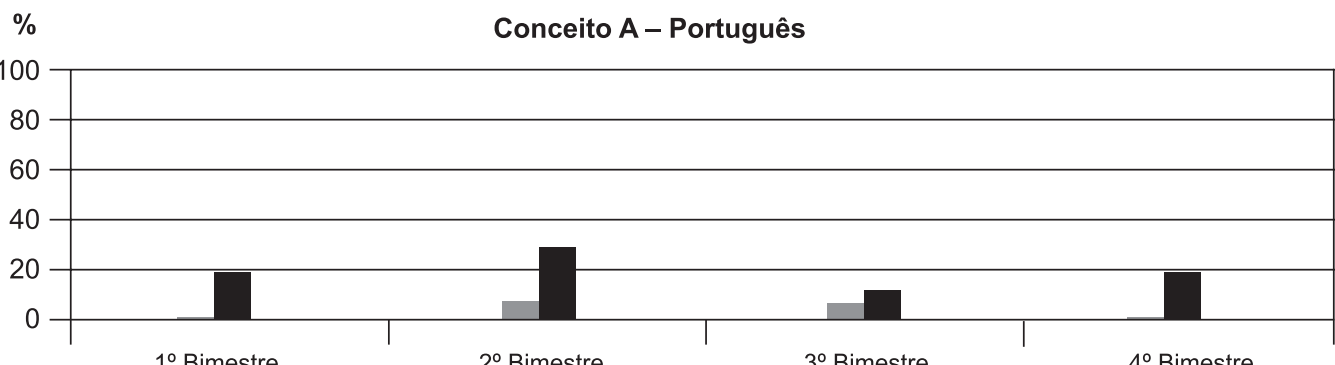

Surdos Ouvintes
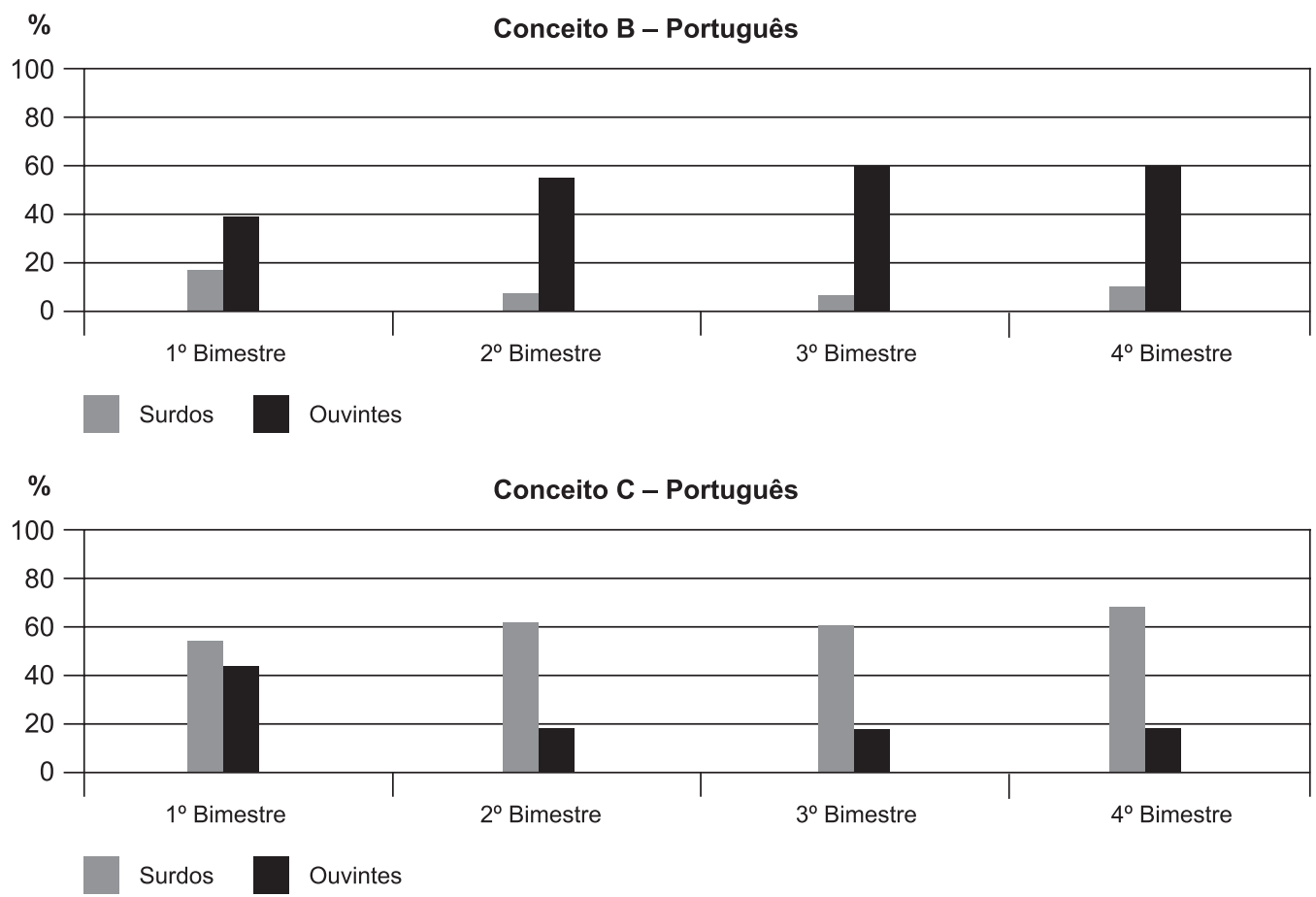

$\%$

Conceito D - Português

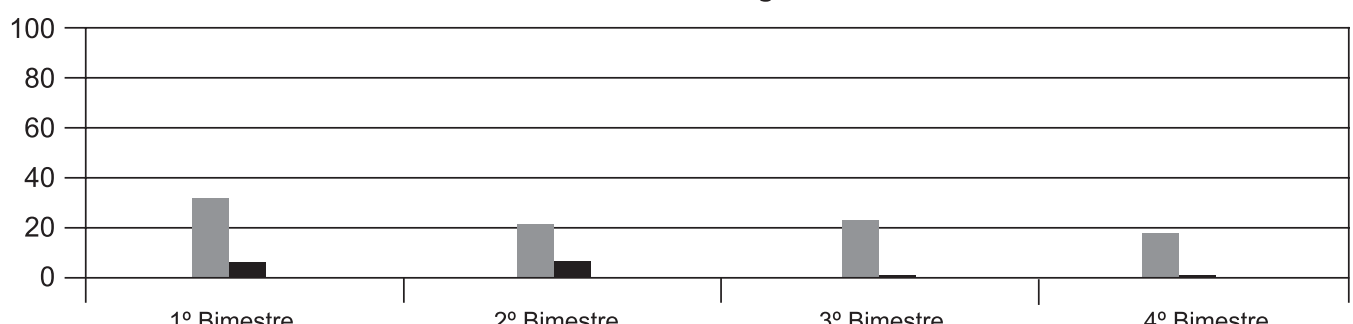

Surdos Ouvintes

Gráfico 8 - Notas acadêmicas obtidas na disciplina de Língua Portuguesa nos quatros bimestres de 2003

Quanto às notas acadêmicas obtidas pelos alunos na disciplina de Matemática, pode-se ter no Gráfico 9 uma visão geral dos conceitos (A, B, C e D) alcançados pelos alunos (surdos e ouvintes) nos diferentes bimestres do ano de 2003.
Observa-se nele a pouca incidência de obtenção do conceito A pelos alunos. De modo geral, constata-se que há maior incidência do conceito B pelos alunos ouvintes e do conceito $\mathrm{C}$ pelos surdos. Quanto à menção D, observa-se que quase somente 

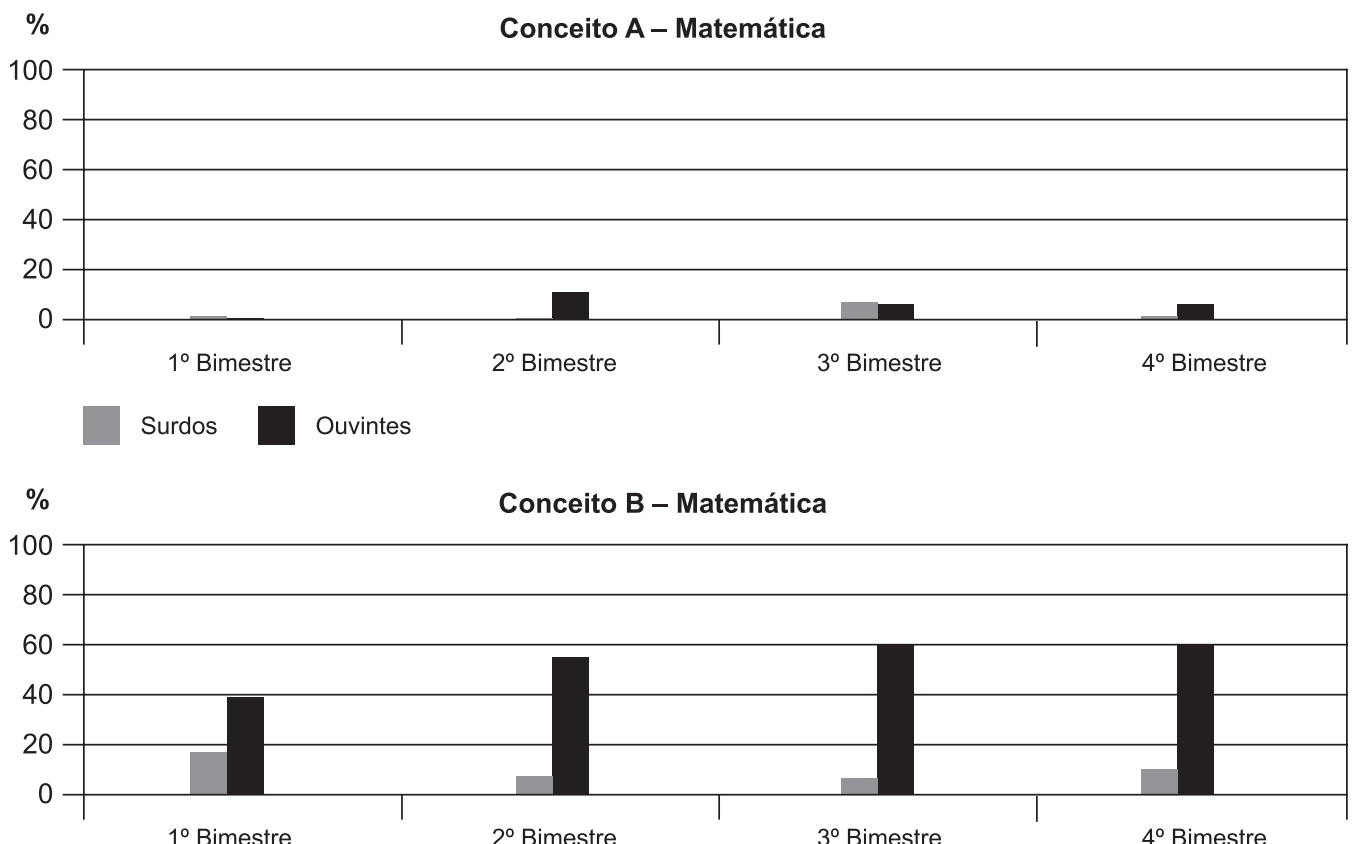

Ouvintes

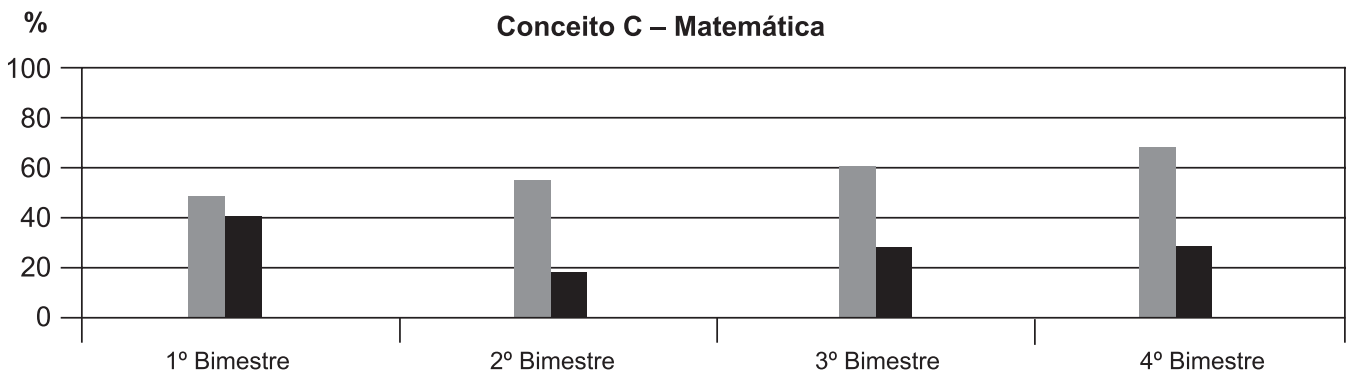

Surdos Ouvintes

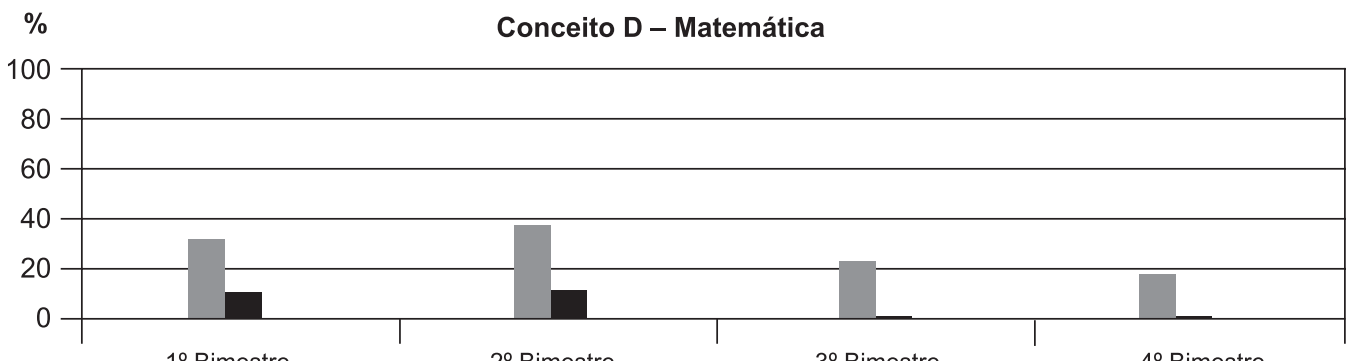

Surdos Ouvintes

Gráfico 9 - Notas acadêmicas obtidas na disciplina de Matemática nos quatros bimestres de 2003

alunos surdos a obtiveram, com poucos alunos ouvintes na mesma condição.

Analisando e comparando os gráficos relativos às disciplinas de Língua Portuguesa e Matemática, nota-se a pouca diferença na incidência dos conceitos obtidos pelos alunos nestas disciplinas. De modo geral, foi observado que os alunos surdos apresentaram notas acadêmicas inferiores às obtidas pelos alunos ouvintes. 


\section{Conclusão}

Conforme menciona Bueno (2001, p. 24), a educação inclusiva é a prática de inclusão de todos os alunos, independentemente de suas deficiências, em escolas e salas de aula adequadas, de modo que haja o aprendizado do conteúdo acadêmico por eles. O desafio desse ensino é o de desenvolver uma pedagogia centrada na criança $\mathrm{e}$ capaz de educar a todo e qualquer aluno no ensino regular. Assim, conclui-se que a inclusão educacional dos alunos com NEEs tem por objetivo o aprendizado do conteúdo acadêmico por todos eles.

Quanto à avaliação da aprendizagem do aluno surdo, pode-se afirmar que é este um ponto merecedor de profunda reflexão. Todos os profissionais envolvidos nesse processo deverão estar conscientes de que o mais importante é que os alunos consigam aplicar os conhecimentos adquiridos em seu dia-a-dia, de forma que esses conhecimentos possibilitem uma existência de qualidade e o pleno exercício de cidadania (O Aluno, p. 2).

Assim, as escolas que têm alunos com NEEs, entre eles os surdos, precisam assegurar-lhes o aprendizado do conteúdo acadêmico, pois, segundo afirma Mendes (2002), por vezes, estes alunos apenas têm acesso a uma carteira comum, em uma escola comum, com uma professora comum, tomando um lugar que nem sempre foi por ele desejado.

O principal obstáculo para a efetiva inclusão de alunos com NEEs está na expectativa do professor quanto à capacidade de aprendizagem dos seus alunos (Bencini, 2001).

No estudo de Silva e Pereira (2003), os professores consideraram que seus alunos surdos apresentavam condições de ter uma aprendizagem normal, no entanto, que ela ocorria de modo diferente, o que evidenciava a baixa expectativa dos professores em relação à aprendizagem dos surdos. O presente estudo constatou também a baixa expectativa dos professores quanto ao aprendizado dos estudantes surdos, se comparado à que apresentavam quanto aos alunos ouvintes.

Deste modo, a fim de verificar se os relatos dos professores eram condizentes com a realidade acadêmica dos alunos, optou-se por comparar as expectativas com as notas acadêmicas, a produção acadêmica, bem como o diário de campo.
Por meio destes elementos, foi constatado que a expectativa dos professores, no que se refere ao desempenho acadêmico dos alunos, coincidia com a realidade por estes apresentada. As notas acadêmicas obtidas pelos alunos surdos, nas duas disciplinas consideradas no estudo, foi inferior às apresentadas pelos estudantes ouvintes. Quanto à produção acadêmica e às anotações do diário de campo, foi verificada, também, diferença entre eles, sendo que os surdos apresentaram mais dificuldades que os alunos ouvintes para realizar as atividades acadêmicas.

Os resultados indicam que as expectativas dos professores quanto ao aspecto acadêmico desses alunos mostrou ser compatível ao apresentado por estes, ou seja, realmente os alunos surdos obtiveram um rendimento acadêmico inferior ao obtido pelos ouvintes. No entanto, a partir disso, podese questionar se o desempenho escolar não sofreu influência da expectativa do professor, pois, conforme afirma Freire (2000), essa expectativa tem um peso determinante no desenvolvimento do aluno, podendo imfluenciá-lo não só naquele momento, mas, também, ao longo de sua vida. Assim, o desenvolvimento acadêmico do aluno pode estar contaminado pela expectativa do professor, sendo que isso apresenta duas faces: enquanto predetermina o comportamento de alguns alunos para o sucesso escolar, predetermina o de outros para o fracasso escolar.

As expectativas transformam-se em teorias moldadas sobre o desempenho do aluno e em profecias de auto-realização. Conforme menciona Juvonen (1988), os professores vêem as causas do fracasso dos alunos como estáveis, reduzindo as expectativas de sucesso e elevando as de fracasso.

Como vimos, este estudo constatou que a expectativa do professor quanto ao aprendizado escolar do alunado pode realmente influenciá-lo. Deste modo, inúmeras são as implicações educacionais deste resultado, tanto no que se refere à formação do professor quanto à sua prática pedagógica e as conseqüentes repercussões no desenvolvimento, aprendizagem e motivação dos alunos.

Os professores geralmente não reconhecem o papel que exercem como elemento fundamental no processo de ensino-aprendizagem. Para que tal não acabe interferindo no desempenho acadêmico dos alunos surdos, faz-se necessário preparar adequadamente os docentes, desmistificando as 
deficiências, esclarecendo-os das possibilidades desses alunos e, sobretudo, mudar o modo de vê-los, para, assim, evidenciar o potencial acadêmico que apresentam; além disso, é preciso também que o professor acredite na sua competência para ensiná-los. Esse preparo poderá trazer subsídios para auxiliar o processo inclusivo, direcionando-o a alcançar a efetividade.

Desta forma, pode-se apontar a necessidade de melhor formação dos professores do ensino regular; é mister que eles se tornem conscientes de suas crenças e dos efeitos que elas exercem sobre o sucesso ou o fracasso escolar dos alunos, com ou sem NEEs.

\section{Referências bibliográficas}

ARTROLLI, A. L. A integração do aluno deficiente na classe comum: a visão do professor. Dissertação (Mestrado em Educação) - Programa de Pós-Graduação da Faculdade de Filosofia e Ciência, Universidade Estadual de São Paulo, Marilia, 1999.

BENCINI, R. Pessoas especiais. Revista Nova Escola, v. 6, n. 39, p. 43, jan./fev. 2001.

BRASIL. Constituição. Constituição da Republica Federativa do Brasil. Brasília, DF: Senado, 1988. p. 118.

BRASIL. Ministério da Educação e Cultura. Lei no 9.394, de 23 de dezembro de 1996. Lei que fixa as Diretrizes e Bases da Educação Nacional Brasileira. Brasília, 1996.

BRASIL. Ministério da Educação e do Desporto. Portaria n. ${ }^{0}$ 1.793, de 27 de dezembro de 1994, proposta de inclusão de ítens ou disciplinas acerca dos portadores de necessidades especiais nos currículos dos cursos de $2^{\circ}$ e $3^{\circ}$ graus. Diário Oficial [da República Federativa do Brasil], Brasília, n. 246, p. 1-33, 28 dez. 1994a.

BRASIL. Ministério da Justiça. Declaração de Salamanca e Linha de Ação sobre Necessidades Educativas Especiais. Brasília: Corde, 1994b.

BUENO, J. G. S. A educação do deficiente auditivo no Brasil: situação atual e perspectivas. Tendências e desafio da educação especial. Brasília: Ministério da Educação e do Desporto, Seesp, 1994. p. 35.

A inclusão de alunos deficientes na classe comum do ensino regular. Temas sobre desenvolvimento, v. 9, n. 54, p. 21-27, 2001.

. Crianças com necessidades educativas especiais, política educacional e a formação de professores: generalistas ou especialistas? Revista Brasileira de Educação Especial, n. 3, p. 12, 1999.

BUFFA, M. J. M. B. A inclusão da criança deficiente auditiva no ensino regular: uma visão do professor de classe comum. Dissertação (Mestrado em Ciências) - Hospital de Reabilitação de Anomalias Craniofaciais, Universidade de São Paulo, Bauru, 2002.

CAPELLINI, V. L. M. F. A inclusão de alunos com necessidades educacionais especiais em classes comuns: avaliação do rendimento acadêmico. Dissertação (Mestrado em Educação Especial) - Programa de Pós Graduação em Educação Especial, Universidade Federal de São Carlos, São Carlos, 2002.

CARVALHO, R. E. A política de integração do deficiente no Brasil. SEE - Projeto de Educação Continuada, proposta de educação especial - $2^{\circ}$ módulo, São Paulo, 1997. p. 18. 
FREIRE, F. A. A interação professor-aluno e suas implicações pedagógicas. Unopar Cient. Ciênc. Hum. Educ., Londrina, v. 1, n. 1, p. 115-121, 2000.

GLAT, R. A integração de portadores de deficiência: uma reflexão. 2. ed. Rio de Janeiro: Sette Letras, 1998. (Questões atuais em educação especial, v. 1).

GLAT, R.; NOGUEIRA, M. L. L. Políticas educacionais e a formação de professores para a educação inclusiva no Brasil. Integração, v. 14, n. 24, p. 22-28, 2002.

GOOD, T. Two decades os research on teacher expectations: findings and future directions. Journal of Teacher Educational, v. 38, n. 4, p. 32-47, 1987.

JUVONEN, J. Outcome and attributional disagreements between students and their teacher. Journal of Educational Psychology, v. 80, n. 3, p. 330-336, 1988.

LEÃO, A. M. C. O processo de inclusão: a formação do professor e sua expectativa quanto ao desempenho acadêmico do aluno surdo. Dissertação (Mestrado em Educação Especial) - Programa de Pós-Graduação em Educação Especial, Universidade Federal de São Carlos, São Carlos, 2004.

MACHESI, A. El dessarollo cognitivo e lingüístico de los nino sordos: perspectivas educativas. Madrid: Aliança Ed., 1987. p. 48.

MANTOAN, M. T. E. Ensino inclusivo/educação de qualidade para todos. Integração. Brasília, n. 20, p. 29-32, 1998.

MARTINI, M. L.; DEL PRETTE, Z. A. P. Atribuições de casualidade para o sucesso e o fracasso escolar dos seus alunos por professoras do ensino fundamental. Interação em psicologia, v. 6, n. 2, p. 149-156, 2002.

MENDES, E. G. Desafios atuais na formação do professor de educação especial. Integração, v. 14, n. 24 , p. $12-17,2002$.

O ALUNO surdo na educação básica superior [on line]. Disponível em: url: http:// www.ines.org.br/ines-livros/Fasc6_PRINCIPAL.HTM. Acessado em: 1 ago. 2003.

PARIZZI, R. A. A pratica pedagógica do professor de educação especial: aprendendo a ensinar com a diversidade. Tese (Doutorado) - Programa de Pós-Graduação em Educação, Universidade Federal de São Carlos, São Carlos, 2000.

PEDROSO, C. C. A. Com a palavra o surdo: aspectos do seu processo de escolarização. Dissertação (Mestrado em Educação Especial) - Programa de Pós Graduação em Educação Especial, Universidade Federal de São Carlos, São Carlos, 2001.

POLLACK, D. Educational audiology for the limited hearing infant and pre-schooler. Springfield, IL, 1985.

QUADROS, R. Educação de surdos: a aquisição da linguagem. Porto Alegre: Artes Médicas, 1997.

REIS, A. C. M. B. Integração da criança portadora de deficiência auditiva no ensino regular: um programa de orientação a professores. Dissertação (Mestrado em Educação Especial) - Programa de Pós-Graduação em Educação Especial, Universidade Federal de São Carlos, São Carlos, 1996.

RIBEIRO, L. C.; BREGUNCI, M. das G. de C. Interação em sala de aula: questões conceituais e metodológicas. Belo Horizonte: UFMG, 1986. p. 13. 
ROSENTHAL, R.; JACOBSON, L. Profecias auto-realizadoras na sala de aula; as expectativas das professoras como determinantes não intencionais da capacidade intelectual dos alunos. In: PATTO, M. H. S. (Org.). Introdução à psicologia escolar. São Paulo: Queiroz, 1983. p. 258-295.

SACALOSKI, M. Inserção do aluno deficiente auditivo no ensino regular: a comparação entre o desempenho dos alunos ouvintes e deficientes auditivos e a visão dos pais, professores e alunos. Tese (Doutorado) - Distúrbios da Comunicação Humana, Escola Paulista de Medicina, São Paulo, 2001.

SASSAKI, R. K. Inclusão: construindo uma sociedade para todos. Rio de Janeiro: WVA, 1997.

SÃO PAULO. Deliberação 3/5/2000. São Paulo: Conselho Estadual de Educação. D.O.E. de 4/5/2000. p. 9-10.

SILVA, A. B. P.; PEREIRA, M. C. C. O aluno surdo na escola regular: imagem e ação do professor. Psicologia: teoria e pesquisa, v. 19, n. 2, p. 173-176, maio/ago. 2003.

STAINBACK, S.; STAINBACK, W. Inclusão: um guia para educadores. Porto Alegre: Artmed, 1999. p. 25.

Andreza Marques de Castro Leão, mestre em Educação Especial pela Universidade Federal de São Carlos (UFSCar), é professora do curso de pós-graduação em Educação Especial da Faculdade de Educação São Luís - Jaboticabal, SP.

andreza_leao@yahoo.com.br

Maria da Piedade Resende da Costa, doutora em Psicologia Experimental pela Universidade de São Paulo (USP), é professora orientadora do Programa de Pos-Graduação em Educação Especial da Universidade Federal de São Carlos (UFSCar).

piedade@power.ufscar.br

\section{Abstract Inclusion: the expections of teachers concerning the academic performance of deaf students}

The present study aims at analyzing the expectations of teachers in relation to school performance of deaf students, comparing it to hearing students, and to verify situations of school success or failure. The instruments used were: a questionnaire, scores in Portuguese and in Mathematics, an analysis of the academic production and field journals. Sixteen teachers of deaf students of public (state and municipal) and private schools in the city of São José dos Campos/SP participated in the study. The teachers evaluated 32 pupils, being 16 deaf and 16 hearing. Concerning the deaf students, one verified that they presented an inferior academic performance when compared to the hearing ones. The scores achieved by deaf students, in the two disciplines considered in the study, were inferior to the ones achieved by hearing students. In relation to the academic production and notations on the field journal, one verified that there was a difference between these pupils, being that the deaf students had presented more difficulties than the hearing students to carry through academic activities. These results point out that the expectations of teachers in relation to the academic performance of these pupils are compatible, i.e, deaf pupils had really presented an inferior academic performance when compared to the hearing students. There are 
innumerable educational implications from this result, as much as it relates to teachers' formation, as to their teaching methods and to the repercussions in the development, learning and motivation of the students. In order not to negatively intervene with the academic performance of deaf students, it is necessary to adequately prepare teachers.

Keywords: inclusion; deaf students; school performance and expectation.

Recebido em 17 de junho de 2005.

Aprovado em 26 de agosto de 2005. 


\section{Anexo 1}

\section{NOTAS ACADÊMICAS DOS ALUNOS SURDOS E OUVINTES}

\begin{tabular}{|c|c|c|c|c|c|c|c|c|}
\hline \multirow{2}{*}{$\begin{array}{l}\text { ALUNOS } \\
\text { SURDOS }\end{array}$} & \multicolumn{2}{|c|}{$1^{\circ}$} & \multicolumn{2}{|c|}{$2^{\circ}$} & \multicolumn{2}{|c|}{$3^{\circ}$} & \multicolumn{2}{|c|}{$4^{\circ}$} \\
\hline & LP & MAT & LP & MAT & LP & MAT & LP & MAT \\
\hline $\mathrm{A} 1$ & $D$ & $D$ & $D$ & $D$ & $D$ & D & $D$ & $D$ \\
\hline A2 & C & C & C & D & D & D & C & C \\
\hline A3 & C & C & C & C & C & C & C & C \\
\hline A4 & C & C & C & C & C & C & C & C \\
\hline A5 & C & C & C & C & C & C & C & C \\
\hline A6 & C & C & C & C & C & C & C & C \\
\hline A7 & D & D & D & $D$ & C & C & C & C \\
\hline A8 & C & C & C & C & C & C & C & C \\
\hline A9 & B & B & B & C & B & B & $B$ & $B$ \\
\hline A10 & B & B & B & B & B & B & & \\
\hline A11 & C & C & C & C & C & C & C & C \\
\hline A12 & D & D & D & D & D & D & $D$ & D \\
\hline A13 & $D$ & D & C & $D$ & C & C & C & C \\
\hline A14 & C & C & C & C & C & C & C & C \\
\hline A15 & $D$ & D & D & $D$ & D & D & $D$ & $D$ \\
\hline A16 & B & B & A & B & A & A & B & B \\
\hline \multirow{2}{*}{$\begin{array}{l}\text { ALUNOS } \\
\text { OUVINTES }\end{array}$} & \multicolumn{2}{|c|}{$1^{\circ}$} & \multicolumn{2}{|c|}{$2^{\circ}$} & \multicolumn{2}{|c|}{$3^{\circ}$} & \multicolumn{2}{|c|}{$4^{\circ}$} \\
\hline & LP & MAT & LP & MAT & LP & MAT & LP & MAT \\
\hline A17 & C & D & C & C & C & C & C & $C$ \\
\hline A18 & D & D & D & D & C & C & C & C \\
\hline A19 & C & C & B & B & B & B & B & B \\
\hline A20 & C & C & C & B & B & B & B & B \\
\hline A21 & C & C & B & C & B & B & B & B \\
\hline A22 & C & C & B & $B$ & B & B & $B$ & $B$ \\
\hline A23 & C & C & B & B & C & C & C & C \\
\hline A24 & A & B & A & $A$ & A & B & A & B \\
\hline A25 & C & C & C & C & B & C & B & C \\
\hline A26 & B & B & B & $D$ & B & C & $B$ & C \\
\hline A27 & B & B & B & B & B & B & B & B \\
\hline A28 & B & B & A & B & B & B & B & $B$ \\
\hline A29 & B & B & A & B & B & B & B & B \\
\hline A30 & A & B & A & A & B & B & A & A \\
\hline A31 & B & C & B & B & B & B & B & B \\
\hline A32 & A & B & A & B & A & A & A & B \\
\hline
\end{tabular}




\section{Anexo 2}

\section{AVALIAÇÃO DOS ALUNOS}

\begin{tabular}{|c|c|}
\hline Nome: & Sexo: \\
\hline Idade: & Série: \\
\hline Escola: & Cidade: \\
\hline Tipo de perda auditiva: & \\
\hline Faz uso de aparelho de amplificação sonoro individ & Ial (AASI)?（） Sim ( ) Não \\
\hline Tem acompanhamento fonoaudiológico? ( ) Sim. Q & uanto tempo: _ Não ( ) \\
\hline Tem acompanhamento pedagógico? ( ) Sim. Quan & o tempo: — Não ( ) \\
\hline
\end{tabular}

Faça um X na opção que você escolher.

\begin{tabular}{|c|c|c|c|c|c|}
\hline \multicolumn{6}{|c|}{ ACADÊMICO } \\
\hline $\begin{array}{l}\text { 1. De acordo com o } \\
\text { esperado por você, como } \\
\text { está o potencial de } \\
\text { desenvolvimento } \\
\text { acadêmico deste aluno? }\end{array}$ & Muito bom & Bom & Regular & Ruim & Péssimo \\
\hline $\begin{array}{l}\text { 2. Como você classificaria } \\
\text { o rendimento acadêmico } \\
\text { deste aluno quando } \\
\text { comparado ao restante } \\
\text { da classe? }\end{array}$ & $\begin{array}{l}\text { Muito acima } \\
\text { dos escores } \\
\text { dos demais } \\
\text { alunos }\end{array}$ & $\begin{array}{l}\text { Acima dos } \\
\text { escores dos } \\
\text { demais } \\
\text { alunos }\end{array}$ & $\begin{array}{l}\text { Na média dos } \\
\text { escores dos } \\
\text { demais } \\
\text { alunos }\end{array}$ & $\begin{array}{l}\text { Abaixo dos } \\
\text { escores dos } \\
\text { demais } \\
\text { alunos }\end{array}$ & $\begin{array}{l}\text { Bem abaixo } \\
\text { dos demais } \\
\text { alunos }\end{array}$ \\
\hline $\begin{array}{l}\text { 3. Em relação à realização } \\
\text { adequada das tarefas } \\
\text { propostas em classe, como } \\
\text { seu aluno se enquadra? }\end{array}$ & $\begin{array}{l}\text { Muito acima } \\
\text { dos demais } \\
\text { alunos }\end{array}$ & $\begin{array}{l}\text { Acima dos } \\
\text { demais } \\
\text { alunos }\end{array}$ & $\begin{array}{l}\text { Na média dos } \\
\text { demais alunos }\end{array}$ & $\begin{array}{l}\text { Abaixo dos } \\
\text { demais } \\
\text { alunos }\end{array}$ & $\begin{array}{l}\text { Bem abaixo } \\
\text { dos demais } \\
\text { alunos }\end{array}$ \\
\hline $\begin{array}{l}\text { 4. Com que freqüência este } \\
\text { aluno finaliza as tarefas em } \\
\text { classe sozinho? }\end{array}$ & Sempre & Freqüentemente & Às vezes & Raramente & Nunca \\
\hline $\begin{array}{l}\text { 5. Este aluno necessita de } \\
\text { apoio constante para realizar } \\
\text { as tarefas acdêmicas? }\end{array}$ & Sempre & Freqüentemente & Às vezes & Raramente & Nunca \\
\hline $\begin{array}{l}\text { 6. Com relação à } \\
\text { compreensão da matéria, } \\
\text { este aluno precisa de mais } \\
\text { explicações que os demais } \\
\text { alunos? }\end{array}$ & Sempre & Freqüentemente & Às vezes & Raramente & Nunca \\
\hline $\begin{array}{l}\text { 7. Em relação aos trabalhos } \\
\text { acadêmicos mais complexos, } \\
\text { este aluno consegue } \\
\text { realizá-los? }\end{array}$ & Sempre & Freqüentemente & Às vezes & Raramente & Nunca \\
\hline $\begin{array}{l}\text { 8. Quanto às notas } \\
\text { acadêmicas deste aluno, } \\
\text { como tem se mostrado em } \\
\text { relação aos demais alunos? }\end{array}$ & $\begin{array}{l}\text { Muito acima } \\
\text { dos demais } \\
\text { alunos }\end{array}$ & $\begin{array}{l}\text { Acima dos } \\
\text { demais } \\
\text { alunos }\end{array}$ & $\begin{array}{l}\text { Na média dos } \\
\text { demais alunos }\end{array}$ & $\begin{array}{l}\text { Abaixo dos } \\
\text { demais } \\
\text { alunos }\end{array}$ & $\begin{array}{l}\text { Bem abaixo } \\
\text { dos demais } \\
\text { alunos }\end{array}$ \\
\hline $\begin{array}{l}\text { 9. Qual o nível de expectativa } \\
\text { quanto a este aluno quando } \\
\text { comparado ao restante } \\
\text { da sala? }\end{array}$ & $\begin{array}{l}\text { Muito acima } \\
\text { dos demais } \\
\text { alunos }\end{array}$ & $\begin{array}{l}\text { Acima dos } \\
\text { demais } \\
\text { alunos }\end{array}$ & $\begin{array}{l}\text { Na média dos } \\
\text { demais alunos }\end{array}$ & $\begin{array}{l}\text { Abaixo dos } \\
\text { demais } \\
\text { alunos }\end{array}$ & $\begin{array}{l}\text { Bem abaixo } \\
\text { dos demais } \\
\text { alunos }\end{array}$ \\
\hline $\begin{array}{l}\text { 10. Quanto ao desempenho } \\
\text { acadêmico, este aluno tem } \\
\text { correspondido às suas } \\
\text { expectativas e esforços? }\end{array}$ & Sempre & Freqüentemente & Às vezes & Raramente & Nunca \\
\hline $\begin{array}{c}\text { MUITO OBRIGADA } \\
\text { PELA SUA COLABORAÇÃO! }\end{array}$ & & & - & aunto dot) & \\
\hline
\end{tabular}

